\title{
Clinical Spectrum and Surgical Treatment of Acute Abdomen: A Case Study from a Tertiary Hospital in Guntur, India
}

\author{
Shivani Pragada ${ }^{1}$, Eluri Harshavardhan ${ }^{2}$, Satyanavamani ${ }^{3}$ \\ ${ }_{1}^{1} 3^{\text {rd }}$ Year Surgery Post-Graduate, Department of Surgery \& Guntur Medical College, Guntur, Andhra Pradesh, India \\ ${ }^{2} 3^{\text {rd }}$ Year Surgery Post-Graduate, Department of Surgery \& Guntur Medical College, Guntur, Andhra Pradesh, India \\ ${ }^{3}$ Assistant Professor, Department of Surgery, Guntur Medical College, Guntur, Andhra Pradesh, India
}

(Lotus park apartments, lane 3, flat 107, AP Housing board colony, Nallapadu, Near Sai baba temple and Shivam school, Guntur, 522004, Andhra Pradesh

\begin{abstract}
Acute abdomen is one of commonest surgical emergencies which poses a great challenge for diagnosis and management of the cause. Abdomen is stated to be Pandora's magic box, for the difficulty in pre-operative diagnosis and treatment. An observational study was conducted in a tertiary hospital from January 2018 to October 2019 to know the most common etiology of acute abdomen. The term acute abdomen denotes symptoms and signs of intra-abdominal disease usually treated best by surgical operations.
\end{abstract}

Keywords: Acute abdomen is one of commonest surgical emergencies which poses a great challenge for diagnosis and management of the cause. Abdomen is stated to be Pandora's magic box, for the difficulty in pre-operative diagnosis and treatment. An observational study was conducted in a tertiary hospital from January 2018 to October 2019 to know the most common etiology of acute abdomen. The term acute abdomen denotes symptoms and signs of intra-abdominal disease usually treated best by surgical operations.

\section{Introduction}

Acute abdomen refers to symptoms and signs of the inflammatory, infectious or obstructive changes in the abdomen that needs immediate surgical therapy. A thorough work up needs to be done for diagnosis

and management of the patients presenting to the emergency department. Acute abdominal pain is a severe abdominal pain, if accompanied by guarding, rigidity, mostly having features of peritonitis which needs immediate surgical exploration.

The morbidity and mortality mainly depend on early intervention and good post-operative care. Very often an accurate diagnosis cannot be made without surgery and many wonders are revealed on opening the abdomen. Case history and physical examination remains one of the most useful tools in the diagnosis of Gastro-intestinal disease, which are co-related with $\mathrm{x}$-rays, ultrasound abdomen, blood investigations and CT abdomen if needed.

Management of the patients with acute abdomen is not always surgery which is a common mis-conception. The term "acute abdomen" should never be equated with the invariable need for surgery. Surgical management of the patient who has an acute abdomen should be thoroughly investigated, resuscitated and decided for the surgery.

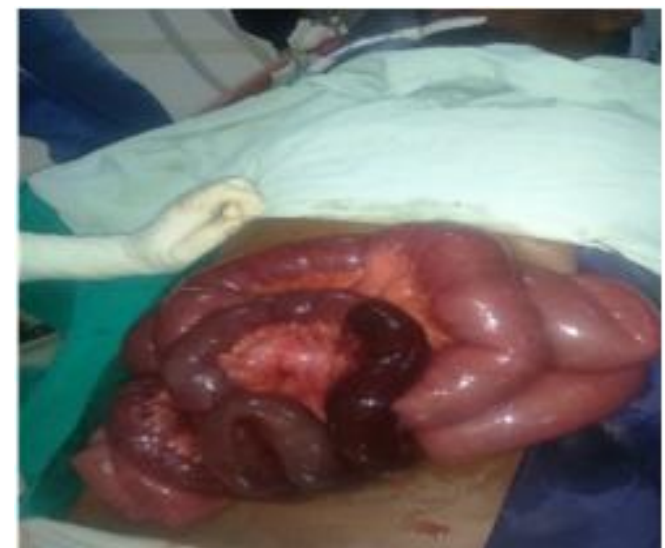

Figure 1: A case of mesenteric ischemia with gangrenous small bowel

The general rule can be laid down that the majority of severe abdominal pains that ensue in patients who have been previously well, and that lasts as long as six hours

\section{Aims and Objectives}

- To study various etiologies of acute abdomen.

- To study various modes of clinical presentation of acute abdomen.

- To study surgical management and post-operative complications of the operated cases.

\section{Case Study}

In the present study, a retrospective study of 100 cases of acute abdomen was conducted from January 2018 to October 2019 in a tertiary care hospital, Government general hospital, Guntur. 


\section{Inclusion criteria:}

- Patients with positive findings in USG and $\mathrm{x}$-ray erect abdomen.

- Patients with acute abdomen, willing for surgery.

\section{Exclusion criteria:}

- Patients with traumatic causes of acute abdomen.

- Patients treated conservatively.

- Pregnant women and children below 13 years with acute abdomen.

In the present study, detailed history and physical examination was done for all acute abdominal emergencies. X-ray erect abdomen, USG and routine blood investigations carried out.

\section{Results}

At Government general hospital,Guntur a retrospective study of 100 cases of acute abdomen was carried out from January 2018 to October 2019 with the following results.

The most common diseases that presented as acute abdomen which required surgical management was acute appendicitis, followed by small bowel obstruction and perforated duodenal ulcer.

Most common surgical procedure carried out was simple closure of the perforation followed by laparoscopic appendectomy.

Table 1: Etiology of Acute Abdomen Cases Which Are Operated

\begin{tabular}{|c|c|c|c|}
\hline Causes of Acute Abdomen & No. & Male & Female \\
\hline Acute appendicitis & 38 & 29 & 9 \\
\hline Perforated duodenal ulcer & 13 & 10 & 3 \\
\hline Gastric perforation & 10 & 6 & 4 \\
\hline Ileal perforation & 7 & 3 & 4 \\
\hline Colonic perforation & 2 & 1 & 1 \\
\hline Small bowel obstruction & 15 & 9 & 6 \\
\hline Large bowel obstruction & 8 & 5 & 3 \\
\hline Acute cholecystitis & 3 & 1 & 2 \\
\hline Ruptured liver abscess & 3 & 3 & 0 \\
\hline GB perforation & 1 & 1 & 0 \\
\hline
\end{tabular}

Table 2: Types of Surgical Procedures Carried Out

\begin{tabular}{|c|c|c|}
\hline Surgical Procedure & No. of Cases & Mortality \\
\hline Open appendicectomy & 12 & 0 \\
\hline Laparoscopic appendicectomy & 25 & 0 \\
\hline $\begin{array}{c}\text { Exploratory laparotomy with primary } \\
\text { closure of the bowel }\end{array}$ & 27 & 5 \\
\hline $\begin{array}{c}\text { Exploratory laparotomy with adhesiolysis } \\
\text { Exploratory laparotomy with resection } \\
\text { and anastomosis }\end{array}$ & 6 & 1 \\
\hline Exploratory laparotomy with ileostomy & 7 & 3 \\
\hline Exploratory laparotomy with colostomy & 3 & 2 \\
\hline Open cholecystectomy & 1 & 0 \\
\hline Laparoscopic cholecystectomy & 3 & 0 \\
\hline Laparotomy procedure with drainage & 3 & 0 \\
\hline
\end{tabular}

If laparoscopicand open appendicectomy are combined,it comprises major number of cases.
Graham's omental patch was most common procedure carried out.

The morbidity was $12 \%$, more in cases of peritonitis.

Late presentation and post-operative complications added to the morbidity and mortality.

The most common post-operative complication was respiratory followed bywound infections and electrolyte disturbances.

\section{Discussion}

Acute abdomen is one of the most common causes of surgical emergencies.

In this study, the most common cause of acute abdomen is acute appendicitis which comprises about $38 \%$ similar to Pandey et al. study. In Jain et al. and Ray et al. studies the most common cause of acute abdomen was perforation peritonitis.

Most of the cases of perforation had features of peritonitis in this study.

Most common cause of perforation was peptic ulcer disease.

Patients presenting with small bowel obstruction were mostly due to bands and inter bowel adhesions followed by mesenteric ischemia and obstructed hernia.

Most common age group at presentation is $30-50$ years.

Males outnumber females by a ratio of 3:1.

Abdominal pain was the most common complaint in all 100 cases followed byvomiting, fever and constipation.

$\mathrm{x}$-ray erect abdomen and ultrasound abdomen were very useful tools for clinching the diagnosis apart from clinical examination.

When compared to developed countries, the presentation of developing countries like India is different and is mostly due to infective and inflammatory cause.

Peritonitis cases were mostly treated by ileostomy as resection and anastomosis would lead to leak. Early ambulation and chest physiotherapywere followed in all cases.

\section{Conclusions}

Acute abdomen is the major cause of surgical emergency and patient has to be thoroughly examined to further proceed to diagnosis and surgery.

Early diagnosis and intervention play an important role in decreasing morbidity and mortality of the patient.

Acute appendicitis was the most common cause of acute 
abdomen in this study with male preponderance.

\section{References}

[1] Jain R, Gupta V. A prospective study of epidemiology and clinical presentation of non-traumatic acute abdomen cases in a tertiary care hospital of central India. Int Surg J. 20163;4(1):242-5.

[2] Irvin TT. Abdominal pain: a surgical audit of 1190 emergency admissions. Br J Surg.

[3] 1989;76:1121-5

[4] Venkateswarlu MC, Chandrika G, Aiswarya, Study of Diseases In Patients With Non Traumatic Acute Abdomen. IOSR. 2015;14(10):15-9

[5] Ray S, Patel M, Parmar H. Management of acute abdomen: Study of 110 cases . IAIM. 2016;4(2): 18-24.

[6] Wellwood J, Johannessen S, Spiegelhalter DJ: How does computer aided diagnosis improve the management of acute abdominal pain.? Ann $\mathrm{R}$ Coll Surg Engl. 1992;74:40-46.

[7] Kauffman GL., Jr. Acute abdomen In: Corson JD Williamson RCN. Editors surgery Mosby, UK 2001;3:3.1 to $3: 3.14$.

[8] NairSK, Singhal VS, Kumar S. Non-traumatic intestinal perforation. Indian J Surg 1981;43(5):371-78.

[9] Mayumi T, et al. The Practice Guidelines for Primary Care of Acute abdomen 2015. Jpn j Radiol., 2015 Dec 18.

[10] Silen W: Cope's Early Diagnosis of the Acute Abdomen, $21^{\text {st }}$ ed. New York, Oxford University Press,2005. 